\title{
Language attrition at the crossroads of brain, mind, and society
}

\author{
Barbara Köpke \\ LABORATOIRE "JACQUES LORDAT" (OCTOGONE), Université TOULOUSE 2
}

\section{Introduction}

The growing interest in language attrition over the past twenty-five years cannot be explained solely on the basis of the fact that most of us are in one way or another affected by the phenomenon. Rather, the focus in attrition has become more and more theoretical since research in this domain has contributed to shed light on the dynamics of bilingual and multilingual language competence and processing (see de Bot, this volume). This may be due to the fact that attrition research is closely linked to other research within this field. First of all, there is the link with studies in language acquisition and learning - which may be considered the reverse of attrition if we expand Jakobson's regression hypothesis (1941) - as documented by a growing number of studies attempting to apply theories of L2 acquisition/learning to L1 attrition (e.g. Gürel 2002; Keijzer 2004; Montrul 2004; Rieussec \& Köpke 2005, 2007; Sharwood Smith \& van Buren 1991). Secondly, attrition has been related to research in language pathology as both are concerned with some kind of language dysfunction (de Bot \& Weltens 1991). Other than Dressler (1991) there are no empirical studies comparing aphasia and attrition (or shift) data, but as we will see in this chapter, a growing number of attrition studies are based on theoretical notions developed to account for bilingual aphasia. Finally, attrition has also been related to diachronic language change and might benefit from parallels drawn with that field (Schmid 2004). One of the specifics of attrition research might well be that it also - and perhaps in a more striking way than the study of language acquisition or pathology - cannot be grasped without taking into account external factors. Attrition, albeit clearly defined as an individual phenomenon (de Bot 2001; Köpke \& Schmid 2004), is intimately linked to social aspects of language use. Consequently, language attrition is a promising research issue for the exploration of links between the brain, mind and external factors that are also of particular interest for research in multilingualism.

Starting from this assumption, the aim of the present chapter is to discuss the predictive values of various factors involved in attrition. Among these are brain mechanisms, cognitive processes and external factors, some of which have already been extensively discussed in the attrition literature. Other factors are discussed here for the first time. The list of factors proposed below is neither 
exhaustive, nor can the discussion of each be more than embryonic. The approach is mainly psycholinguistic, although there will be frequent references to notions arising from the cognitive neuropsychology of bilingualism (Paradis 1997) and to sociolinguistic concepts around bilingualism. I will further follow Nespoulous (1994) in the distinctions of brain mechanisms (discussed in the first part) which are — at least in their original substance — physiologically grounded, and cognitive processes (discussed in the second part) which are involved in the functional architecture of language in the human mind (Nespoulous 1994: 397).

\section{Brain mechanisms}

\subsection{Plasticity}

Plasticity is the most often cited reason for a biologically-constrained critical period for language acquisition and/or learning (see the discussion of this distinction in Ellis 1994; Pallier this volume; Paradis 1994, 2004; Zobl 1995). It is based on the idea that synaptic connections are not fully mature in the first years of life, facilitating quick adaptation to new situations (see the detailed discussions in Pallier, this volume; Ventureyra 2005). This is easily transposable to the immigrant situation: a radical change in the linguistic environment requires adaptation to the new language situation, including learning the host language, in combination with reduced L1 use. The concept of brain plasticity predicts that this adaptation will be easier and quicker the younger the subject (Lenneberg 1967; Penfield \& Roberts 1959). Faster language learning due to greater plasticity might also imply strong L1 attrition in young immigrants, whereas in older immigrants, reduced brain plasticity would both hinder the adaptation to the L2 environment and prevent L1 attrition.

For L2 acquisition and/or learning, such maturational effects have been amply documented (e.g. Birdsong 1992; Flege, Yeni-Komshian \& Liu 1999; Hyltenstam \& Abrahamsson 2003; Johnson \& Newport 1989; see the descriptions in Pallier this volume). L1 attrition data appear to corroborate the hypothesis that age is one of the most predictive factors in attrition (see the literature reviews in Francis 2005; Köpke 2004a; Köpke \& Schmid 2004; Ventureyra, Pallier \& Yoo 2004) since an L2 learned early in life has been reported repeatedly to quickly replace another language, while in later bilinguals the L1 appears largely impervious to erosion. Whether this is due to greater stabilization of linguistic competence in older subjects or not, however, still needs to be demonstrated.

\subsection{Activation thresholds}


The activation mechanism (Luria 1966, 1974) is one of the best known brain mechanisms and has been used, metaphorically, for the cognitive modelling of language processing, especially monolingual and bilingual lexical access (for monolingual access e.g. Dell 1986; McClelland \& Rumelhart 1981; McClelland \& Elman 1986, for bilingual access e.g. Grainger \& Dijkstra 1992; Grosjean 1988). Activation was invoked as a neuronal basis of memory (comprising concepts and linguistic sound forms) half a century ago: "Each passage of a stream of neuronal impulses leaves behind it a persisting facilitation, so that impulses may pass that way again with greater ease" (Penfield \& Roberts 1959: 246). The idea that frequency of use entails facilitation of activation is further developed in Paradis' Activation Threshold Hypothesis (Paradis 2004; this volume) which assumes that a certain amount of neural impulses is needed in order to reach activation. This framework has been shown to account for differential inhibition in polyglot aphasia, and also for the control over two competing language systems in healthy bilinguals (Paradis 1985, 1993, 2004).

Since the activation threshold of any item stored in memory is dependent upon frequency and recency of previous activation, the most important predictive factor for language attrition within this framework is language use (Paradis this volume). To be more precise, those L2 items or rules more frequently used will be more easily activated when they are in competition with less frequently used L1 items or rules. This principle has been shown to be valid for the lexicon in Köpke (2002). Concerning grammatical parameters, it has been clearly demonstrated with respect to Turkish and English binding properties by Gürel (2004; this volume) that attrition occurs where both languages have equivalent forms which may compete, but not where there are no equivalent forms in both languages, so any competition between them is precluded. These findings underscore the validity of the notion of frequency of use in attrition, but also the necessity to interpret findings within a rigorous linguistic framework in order to account for grammatical attrition. The lack of the latter might be the reason why there is not more experimental evidence for the role of language use, although this factor is systematically presumed to play a major role.

\subsection{Inhibition}

Inhibitory neural cells inhibit the electric activity of the neural cells with which they establish contact (Fabbro 1999: 70). As an important means of controlling neural activity, the inhibition mechanism is is ubiquitous in the nervous system (Boujon 2002; Green 1998b). Inhibition and activation have been linked in cognitive models of language processing, within unilingual (see Berg \& Schade 1992 for an overview) and bilingual models alike (e.g. Green 1986, 1998b; Paradis 2004, this volume). It has been argued that "... a combination of excitatory and inhibitory processes is more efficient in achieving selection than excitatory processes alone" (Green 1998b: 102). From a 
cognitive point of view, inhibition can be defined as "... the negative effect the processing of a given item has upon the activation value of another" (Berg \& Schade 1992: 406) ${ }^{1}$. It helps to prevent activation from spreading to too many parts of the system and allows for temporarily stable representations. As such, it plays a key role in any instance of mental control (Green 1986) since it is needed in order to cancel out competitors that are likely to interfere with a selected item, structure, or language (Green 1986: 217; Green 1993: 264). Consequently, inhibition is likely to be a key mechanism in situations where maximum interference is to be expected such as L2 learning, L1 attrition, or polyglot aphasia (Ijalba, Obler \& Chengappa 2004). However, the inhibition mechanism has received less attention than activation in these fields.

In the context of polyglot aphasia, Green claims that the patients' inability to use one language spontaneously is not due to lack of activation but to the inability "... to suppress sufficiently the activation of the other system" (Green 1986: 220), in other words, to lack of inhibitory resources. It is possible that a similar mechanism is at work in the case of L1 attrition. Two means of deselecting a language can be hypothesized in non-pathological contexts: either through a lowering of activation (which is the automatic consequence of non-use and hence dependent on time rather than on resource) or through inhibition (which can be obtained rapidly at the expense of resources). Consequently, for the L1 attriter, the use of the L1 may be doubly impeded: by lack of activation of L1 on the one hand and the need to strongly inhibit the highly active L2 on the other. The precise impact of inhibition mechanisms, however, would depend on several factors, namely: (a) Actual language use including use of each language, language mode, codeswitching, and probably also attitudes to mixed language, etc. (see 3.3. below) (b) Typological relatedness of the languages: the closer the languages and the more structures they share, the more interference is to be expected.

The predictions that can be inferred from this imply that inhibition, as a crucial mechanism allowing the 'separation' of languages, may account for different outcomes of attrition:

- In immigrants who have no contact with other immigrants and who never use L1, L1 will be completely dormant (Green 1986; Norman \& Shallice 1986) resulting in both accessing and processing difficulties arising from the fact that a large proportion of the available resources will be consumed for the inhibition of the very active L2. Conversely there will not be much interference in terms of errors since both languages have very different activation states.

- In immigrants who have frequent contact with other bilingual immigrants and who are used to operating in a bilingual mode, both L1 and L2 are active. Hence L1 will be less difficult

\footnotetext{
${ }^{1}$ Note however that in this definition inhibition appears as a kind of side-effect of the activation of another item, unlike Green's framework which clearly sees inhibition as an active and resource-consuming mechanism.
} 
to access but its use will contain much more interference (see Köpke 2001 for an illustration of both cases and Schmid, this volume, for further discussion of this point).

- In addition, inhibition might explain why recent immigrants are sometimes reported to experience difficulties in L1: since they are still in the process of learning the L2, they have to inhibit their more dominant L1 very strongly, leading to processing difficulties which will appear similar to attrition. Some evidence supporting such an explanation comes from studies on language switching where a higher switch cost has been observed when individuals have to switch into the dominant language compared to switches into the nondominant language (Green 1998a; Meuter \& Humphreys 1997).

\subsection{Involvement of subcortical structures}

Language processing is not only a matter of the cortical structures of the left (grammar) and right (pragmatics) hemispheres, subcortical brain structures have also been found to participate in language processing (Crosson, Novack \& Trenerry 1988), though their role is still difficult to define. The limbic system - as one of the most ancient parts of the brain - is the centre of the communicative functions network in primates and also plays a major role in human communication (Damasio 2003). It is supposed that parts of it, e.g. certain structures of the left basal ganglia and of the left thalamus, participate in the first stages of verbal expression and, most importantly, that the limbic system plays a major role in many control functions, both motor and cognitive (Fabbro 1999: 79). Moreover, subcortical structures have also been shown to be the seat of emotion in the brain (Fabbro 1999; Pavlenko 2005). Clinical evidence suggests that the subcortical structures of the right hemisphere play a role in the regulation of automatic speech of high emotional significance (e.g. prayers, see Speedie, Wertman, Ta'ir \& Heilman 1993), while Pavlenko (2005: 154) claims a participation of the limbic system in spontaneous emotional speech. Hence, communication and language on the one side and emotion on the other share some neuroanatomical structures.

The relation between emotion and language and the consequences this may have for a specific language is of primary interest for attrition research. Pavlenko (2005) claims that this link should best be studied in bilingual or multilingual subjects because they provide the unique opportunity to compare verbal behaviour and emotional reactions across languages. She stresses (2005: 153) that "(...) depending on their linguistic trajectories, bi- and multilinguals may have different neurophysiological responses to their respective languages, or, at least, to emotion-related words" (such as taboo or swearwords for instance). Words of a specific language are linked to personal fears, or experience of prohibition, punishment or reward, and these contribute to the individual's "(...) perception of language embodiment, whereby words invoke both sensory images and 
physiological reactions" (Pavlenko 2005: 155). Research on such aspects of bi-or multilingualism, however, is still scarce (see Pavlenko 2005 for an extensive review).

Emotional implication has received more attention with respect to language acquisition, or learning. For Schumann (1997), language acquisition is favoured by positive emotional values which allow the establishment of links with deeper brain structures. This is also the point of view of Lamendella (1977) and Paradis $(1994,2004)$ who suggest that the L1 is generally based more solidly on the limbic system and its emotional values, whereas L2 learning, particularly when it takes place in the classroom, is largely based on the mere cognitive processes of the neocortical areas (cf. also the discussion on procedural vs. declarative memory below). Similarly, Pavlenko (2005: 156) distinguishes between embodied languages, acquired within an emotional and contextualized process, and disembodied languages, learned in a decontextualized process such as FL classroom learning. But she does stress that both constitute the extremes of a continuum and that emotional implication is not restricted to the L1, particularly when the L2 becomes the basis of a person's affective life. She suggests, therefore, that affective linguistic conditioning is a life-long enterprise (Pavlenko 2005: 157).

This point is of particular interest for attrition research. Even though the relationship between emotional impact and attrition still remains unknown, there is data suggesting that language learning and attrition may rely on a similar biological base. Especially cases where particularly traumatic circumstances obtain (see Schmid 2002; or the studies conducted with adopted children: de Bode 1996; Isurin 2000; Nicoladis \& Grabois 2002; Pallier, Dehaene, Poline, LeBihan, Argenti, Dupoux \& Mehler 2003; Ventureyra 2005) suggest that strong emotional events may have serious consequences. This allows the assumption that the motivation for maintaining a language is similar to the motivation for language learning, and that both these situations entail high emotional values which may be related to subcortical brain structures. Emotion is most likely a key factor in any case of attrition (cf. also the life-span perspective taken by de Bot this volume), and it may well play an even bigger role in language attrition than in language acquisition or learning. The possible prediction arising from this is that L1 attrition would occur only in cases in which either the L2 is strongly emotionally "invested" (which does not necessarily entail more success in L2 learning), or the L1 is strongly rejected (after traumatic experiences such as for example persecution, abandonment, betrayal, or rape).

In sum, attrition seems to be dependent upon four principal brain mechanisms:

- plasticity, which is a function of the age of onset of bilingualism and/or attrition

- activation, which is a function of frequency of language use

- inhibition, which is a function of type of language use 
- subcortical involvement, which is a function of emotional implication

These seem also to be reflected in the cognitive processes implied in language attrition.

\section{Cognitive processes}

\subsection{Memory}

Memory can be related to attrition in a number of ways. The first notion which has to be considered is long term memory (LTM) where linguistic knowledge is stored over time just as many other kinds of knowledge (e.g. arithmetic, historical facts, playing chess, driving a bicycle). If the information stored in LTM is not activated regularly, it might be forgotten. But forgetting may be caused by multiple mechanisms which can contribute in different ways to an explanation of the forgetting of a language. This aspect will be discussed in the first section 2.1.1. Second, as the kind of information stored in LTM is of diverse nature, cognitive psychology has further divided LTM into structurally and functionally distinct subcomponents according to the kind of material which will be stored, the way this is done and how the information will be accessed. Among these, the distinction between procedural and declarative memory (Paradis 1994; Ullman 2001) is of particular interest for attrition research (see below section 2.1.2). Third, the role of memory in language processing in general and in attrition in particular is not restricted to the long term retention of linguistic information in LTM. Memory processes are also involved in online processing of information and control of two language systems (see 1.2. and 1.3.). Such functions rely on working memory (WM) - usually defined as "... a limited capacity system responsible for the temporary storage and processing of information while cognitive tasks are performed" (Collette, van der Linden \& Poncelet 2000: 46). In Baddeley's original conception (1986), WM is composed of two peripherally-based storage systems (the phonological loop and the visuospatial sketchpad) and a central administrator - called central executive in more recent developments of the model (Baddeley 2000, 2003) - whose role is, roughly speaking, to coordinate the whole thing and to allocate attentional resources. The third section (2.1.3) is an attempt to elaborate on a possible role of WM, and more specifically the central executive functions, in attrition.

\subsubsection{Forgetting}

MacLeod (1976) used the savings paradigm focussing on the kind of residual information (phonological form vs. semantic information vs. information on the language the word was in) in the memory traces of L1 and L2 words which could not be recalled five weeks after memorisation 
(see also de Bot \& Stoessel 2000 for L2 attrition). The results seem to suggest that, over time, meaning is retained more easily than form and language information. However, this and other similar studies (see Ammerlaan 1996 for a detailed review) are not really instructive for L1 attrition research because they do not so much investigate the forgetting of a language, but, rather, the retention of linguistic material (see 2.1.2 below). From another perspective, closer to attrition, Bahrick (1984) investigated the retention of school Spanish in Anglophones who had stopped learning Spanish between 1 and 50 years earlier. The results indicate that forgetting slows down as time passes. Moreover, for participants who had higher L2 proficiency at the end of their Spanish curriculum, there was an initial period where L2 knowledge remained stable before slowly starting to vanish. Written comprehension was less affected by forgetting than all other skills. However, this study also focused on the retention of formally-acquired L2 knowledge. The only studies concerning an L1 are based on hypnosis data (As 1963; Fromm 1970, see also Footnick, this volume). The fact that As and Fromm show that their patients are able to recover an otherwise completely forgotten L1 under hypnosis suggests that, in some cases, even total L1 attrition remains a question of retrieval failure, i.e. attrition at the performance level. What all these studies show is that language attrition might be tackled as a memory problem.

In his detailed discussion of different forgetting theories within the context of L1 attrition, Ecke (2004) distinguishes different processes: decay, interference, regression and suppression, distortion, retrieval slowdown and failure, cue dependency, and interaction and dynamic systems. Of course, many of these processes are likely to be interrelated (decay can cause retrieval slowdown or failure, etc.). The predictions arising from these theories are discussed in detail, suggesting that the L1 attrition literature provides plausible examples for all of these processes. So, the most important point of this discussion is that, similar to forgetting, there is not just one possible process of attrition, but rather a variety of processes which are likely to be influenced by a multitude of factors allowing for many different predictions.

\subsubsection{Declarative and procedural memory}

Despite the extensive discussion of the distinction between declarative and procedural LTM and its relevance for bilingualism by Paradis (e.g. 1994, 2004) and Ullman (2001), this distinction has not received the attention it deserves in all domains of research on bilingualism. The only study which applies this concept does so in the context of polyglot aphasia (Ijalba, Obler \& Chengappa 2004: $80)$.

Following Ullman's definitions (2001: 106), declarative memory is involved in the learning and use of knowledge about facts and events and seems to be particularly suited for arbitrarily related information via associative or contextual binding. Procedural memory is involved in the learning 
and control of cognitive and motor skills and habits, which are typically based on sequences. Both memory systems rely on distinct neurofunctional and neuroanatomical structures (Paradis 1994; Ullman 2001). With respect to bilingualism, the declarative/procedural model predicts a difference in the memory structures involved in the processing of grammatical structures in earlier vs. laterlearned languages. Whereas the lexicon is stored in the associative structures of declarative memory for all languages, the implication of procedural memory in the processing of grammar would depend on age of acquisition (since declarative memory plays an increasing role in later language learning) and proficiency (since a language that has been less automatized by the speaker is more likely to be processed declaratively). Roughly, the lexicon of an L1 and a later-learned L2 are likely to be located in the same memory structures (declarative memory) whereas the grammars of an earlier-learned L1 and a later-learned L2 are likely to depend on different memory systems (procedural memory for L1, declarative memory for L2). There would, however, be no differences between the two languages of early bilinguals, as corroborated by data from brain imaging studies with bilinguals (e.g. the reviews in Köpke 1999, 2004a; Ullman 2001), from polyglot aphasia (Ijalba et al. 2004), and specific language impairment (Ullman 2001: 109), among others.

If we take into account the assumption that interference or competition arises only between structures that are similar in nature, this would allow the following predictions with respect to L1 attrition: (a) vocabulary, which is declarative for both languages, is a good candidate for interference in both early and late bilinguals; (b) as far as grammar is concerned, in contrast, interference is expected to be more pronounced in early bilinguals. For late bilinguals, the largely declarative L2 grammar is less likely to interfere with the procedural L1 grammar.

These predictions are not incompatible with L1 attrition data so far: studies with late bilinguals suggest that the lexicon is affected more strongly by L1 attrition than the grammar (e.g. Köpke 2002). Furthermore, it is striking that studies about early bilinguals (mostly case studies) frequently focus on morphology or syntax (e.g. Håkansson 1995; Kaufman \& Aronoff 1991; Levine 1996; Schmitt 2004; Seliger 1991; Turian \& Altenberg 1991; Vago 1991), compared to studies with late bilinguals, which are mainly concerned with more general features (e.g. Ben Rafael 2004; Gross 2004; Köpke 1999; Yagmur 1997) or focus on the lexicon only (e.g. Ammerlaan 1996; Hulsen 2000; Olshtain \& Barzilay 1991; Pavlenko 2003).

\subsubsection{Working memory}

The role of working memory in language processing is still controversial. Apart from a possible role as an emergency resource in case of cognitive overload (McCarthy \& Warrington 1994: 345), it is generally assumed that higher working memory capacity is related to higher comprehension skills, both in listening and reading comprehension (Daneman \& Carpenter 1980; Just \& Carpenter 
1992; McCarthy \& Warrington 1994), but its role in language production has received much less attention, at least as far as unilingual language production is concerned. The most likely assumption is that WM - and specifically the central executive of WM (Baddeley 1986, 2000, 2003) - plays a role in tasks involving high levels of cognitive control. Among the mechanisms associated with the central executive is inhibition (van der Linden \& Colette 2002) which has already been discussed in 1.3.

In bilinguals the need for a control mechanism in online speech production is much more obvious than in unilinguals (e.g. for the L2 learner: Bialystok \& Sharwood Smith 1985) since the use of the two languages needs to be controlled according to language mode (Grosjean 1992). Recall that inhibition (see above 1.3) has been claimed to be the mechanism exercising control over the two competing language systems in bilingual language processing (Green 1986, 1998a, 1998b). This might point to the central executive of WM having a possible role in the control functions involved in bilingual speech, especially in situations where higher control demands arise, e.g. when one language is much more accessible than the other. In a similar vein, it has recently been proposed that interference would not so much be a side-effect of learning, but arise from mental and behavioural control (Anderson 2003: 416). In this view, forgetting would result from "...inhibitory control mechanisms recruited to override prepotent responses." (Anderson 2003: 415).

It is possible that this also has implications for predictions concerning L1 attrition. Strong cognitive demands arising from reduced access to the less-used L1 and from its competition with the more accessible L2 would put strong demands on executive control mechanisms, resulting in processing difficulties similar to those found in L2 learners: an inability to activate automatic procedures (Norman \& Shallice 1986), thereby triggering controlled strategic behaviour which is much slower and characterized by dysfluencies. Attrition would thus, to a large extent, be a processing issue, as has been suggested repeatedly in discussions of the competence/performance issue (e.g. Sharwood Smith this volume). Although this is among the oldest (and probably most complex) theoretical issues in attrition research (e.g. reviews in Köpke \& Schmid 2004; Sharwood Smith 1983) experimental studies investigating attrition from that angle are still scarce (among the exceptions see Dussias 2004).

\subsection{Language aptitude}

A further cognitive skill which may be relevant to language attrition but has not so far been investigated in this context is language aptitude. Within research on L2 acquisition, this concept has been defined as the potential or talent a person has for learning foreign languages (e.g. Carroll 1973; Krashen 1981). It has been found to vary considerably between individuals, while remaining 
relatively independent of other cognitive factors such as general intelligence (Abrahamsson \& Hyltenstam 2005). Language aptitude is a composite measure established through a variety of independent variables including phonetic encoding, grammatical sensitivity and phonetic memory (e.g. Meara, Milton \& Lorenzo-Dus 2003) which have been found to correlate with success in language learning. Recently, Abrahamsson \& Hyltenstam (2005) investigated whether language aptitude could account for exceptional L2 achievement in late learners by correlating it to grammaticality judgement scores in Spanish L2 speakers of Swedish who were carefully screened for a native-like command of L2 Swedish. The results confirmed that a high level of language aptitude appears to be a necessary condition for near-native L2 attainment in adulthood. This finding is interpreted as evidence for maturational constraints which can only be overcome by exceptional language learning aptitude.

The implications of aptitude for L1 attrition have not yet been discussed, all the more since L2 proficiency is not usually assessed in attrition research. The concept of language aptitude is nevertheless promising for attrition research and might be better suited to capture individual variation in attrition than e.g. education level (see the discussion in Köpke \& Schmid 2004: 10-12). The predictions ensuing from this for attrition are that greater language aptitude, which is generally assumed to lead to higher L2 proficiency, could prevent attrition — at least to some degree. Note that such a prediction is in contradiction with proficiency-based accounts (Opitz 2005) e.g. within the multicompetence model (Cook 1992): these accounts predict more L1 attrition in more proficient L2 speakers, whereas an aptitude-based account predicts less L1 attrition in these cases. This issue should remain one of the challenges in L1 attrition research for the next years.

\subsection{Literacy}

From a more psycholinguistic perspective, it has been proposed that literacy might contribute to the cognitive organisation of language and contribute to age effects observed in L1 attrition together with other factors, such as brain plasticity and type of memory involved in language learning (Köpke 2004). Literacy can be seen as a factor which might prevent attrition in several ways. On the sociolinguistic level, literacy (a) allows the speaker to maintain contact with the L1 by reading, which might be an important source of confirming evidence for the L1 (see Sharwood Smith \& van Buren 1991; see below 3.3 for a more detailed discussion of this aspect); and (b) the wish to have access to written input may enhance motivation for maintaining the L1. But more importantly, from the neurofunctional and psycholinguistic perspective, (c) it is likely that literacy contributes to the grounding of a language in memory as it adds orthographic representations and new synaptic connections. However, these effects are closely related to age, and distinguishing the factors 
literacy and age in an experimental setting raises methodological problems that might be difficult to overcome. It can nevertheless be claimed that less attrition is to be expected in subjects who have had the opportunity to become literate in the L1, especially if they frequently use that skill, a suggestion made before by Olshtain (1986) in order to explain her findings in L2 attrition. While the methodological difficulties associated with the actual testing of this factor may be insolvable, this aspect should nevertheless be kept in mind.

\subsection{Task dependency}

Last but not least, attrition of oral production skills is largely a question of online processing (see above) and as such is directly dependent upon task demands. Different language tasks with different cognitive demands do not yield the same results, even if exactly the same linguistic structures are tested. It has been shown, for example, that lexical access in a picture/word matching task is easier than lexical retrieval in a naming task (Ammerlaan 1996; Hulsen 2000), two tasks with very different requirements regarding the level of activation needed for their accomplishment. Similarly, Major (1992) found that L1 VOT was closer to native standards in a more formal readaloud task than in informal spontaneous speech. Köpke (1999) showed that interference was stronger in a grammaticality judgement task than in an oral sentence generation task testing the same grammatical structures ${ }^{2}$.

The issue of task dependency certainly is a methodological question, but it also raises important theoretical issues. Paradis (2004: 11) relates differential behaviour observed between online and offline language tasks to the type of memory structures involved (procedural vs. declarative) in the resolution of a task. So, in some cases, task dependent differences in linguistic behaviour are due to the fact that some tasks allow for the use of metalinguistic knowledge, whereas others do not. But variation in linguistic behaviour may be accounted for in different ways, depending on the theoretical framework of the analysis: the psycholinguistic account relates variation to different task demands (e.g. leading to different activation levels required as in Ammerlaan 1996) or to different task goals as perceived by the subject (e.g. focus on form in a formal read-aloud task as in Major 1992). The linguistic account would be to take variation as indicative of some sort of optionality developing in the linguistic system of the attriter (e.g. Tsimpli this volume). It is perhaps worth considering the possibility that these different accounts may not merely be the outcomes of different theoretical frames, but that they may reflect the complementarity of several factors within a more global approach of attrition. Such considerations bring us back to the competence and performance

\footnotetext{
2 The question of what exactly is actually measured by grammaticality judgements has furthermore been extensively debated (Altenberg \& Vago 2004) in the context of attrition.
} 
distinction (Chomsky 1965; Fodor \& Garrett 1966; Sharwood Smith \& van Buren 1991) discussed below. Since precise predictions arising from the issue of task dependency need to be discussed with respect to each specific task, further discussion of this issue is beyond the scope of this chapter.

In sum, it appears reasonable to assume that attrition is cumulatively predicted by

a) internal cognitive factors arising, for example, from characteristics of the memory structures underlying linguistic competence,

b) structural organisation of the linguistic system (in relation namely with literacy) and

c) linguistic aptitude of the subject

together with more task dependent factors. Many of these cognitive aspects are closely linked to brain mechanisms and depend on constraints due to the characteristics of the human brain and mind. But the claim in what follows will be that the human mind does not develop in complete isolation, but rather in permanent interaction with the subject's social environment.

\section{External factors}

Linguistic development over the lifespan follows internal constraints related to the characteristics of the human brain and mind, but these constraints merely represent opportunities which may or may not be realised as a response to environmental conditions. However, since neuro- or psycholinguistic factors and social conditions are closely linked, this is the point where the snake starts biting its tail: the discussion of most of these aspects and the predictions they allow has been initiated above. The discussions that follow will thus be restricted to the aspects that have not been developed yet.

\subsection{Language use}

The issue of language use has already been considered extensively in relation with activation and inhibition (see 1.2. and 1.3.). Language use has often been assumed to be an important predicting factor for language attrition and is often implicitly invoked by empirical work (see Köpke 2004 and Köpke \& Schmid 2004 for detailed reviews), even though it is difficult to measure. It has previously been proposed to be the key variable at the interface of the psycholinguistic and sociolinguistic aspects of attrition (de Bot 2001). However, the focus has been on quantitative aspects of language use, e.g. amount of contact or frequency of L1 use (but see Schmid this 
volume). Intuitively, it makes sense that individuals who make little use of a language suffer more from attrition than speakers who use the language more frequently, and frequency of L1 use is also a crucial aspect in theoretical models in the context of the Activation Threshold Hypothesis. The discussion of the inhibition mechanism, however, clearly shows that frequency of use is not the only aspect of use that matters. As stressed also by Schmid (this volume) quality of use, or type of contact, is equally important, and this aspect has received hardly any attention.

First of all, a distinction needs to be applied to the use of productive skills and receptive skills. In other words, is active language use (i.e. in production) necessary in order to prevent the L1 from deteriorating, or is regular input sufficient to maintain a language once completely mastered? This question is reminiscent of the discussion around input and output in SLA research (e.g. Swain 2000) and was first invoked in that context by Sharwood Smith and van Buren, who propose that "...the native speaker not only needs evidence for developing an L1 system but also needs evidence to maintain his or her L1." (1991: 23). In this view, input would be crucial for the maintenance of a language. This implies also that input might be sufficient, for example in the case of a speaker who has no opportunity to interact with other L1 speakers but may nevertheless maintain the L1 by written exchanges, or simply by input received from books, films or the internet. Secondly, this raises the question of the quality of that input, which may to some degree be dependent on the sociolinguistic environment of the immigrant (see below). Predictions arising from qualitative aspects of contact are discussed in detail by Schmid (this volume).

\subsection{The cultural context of the immigrant}

The relationship between cognition and culture is illustrated in Sperber and Hischfeld's (to appear) theory, where it is claimed that culture arises from Social Cognitive Causal Chains (SCCC) ${ }^{3}$ establishing semantic relationships between people. These SCCCs allow for stabilizing representations and practice within a given community. This view implies that these representations concern - among many other things - language status (see 3.3 below), but also linguistic and pragmatic norms. In other words, SCCCs would include linguistic and pragmatic input as discussed by Sharwood Smith and van Buren (1991). Adopting Sperber and Hischfeld's view, it can be claimed that immigrants are cut off from the SCCCs of the L1 community and no longer have any support in stabilizing their L1 representations and practice. This resembles Sharwood Smith's and van Buren's suggestion that (1991: 23): "...the L1 changes not because of lack of use but because of lack of confirming evidence that L1 is the way it is in the L1 community"

\footnotetext{
${ }^{3}$ Following Sperber and Hirschfeld (to appear), causal chains of culture consist in an alternation of mental and public episodes, both of which are linked through imitation and communication.
} 
(my emphasis). The input, or lack thereof, of the L1 community would hence be the critical factor in L1 attrition, and this is likely to be particularly true with respect to the attrition of pragmatic norms (an area of language attrition which is very much under-researched).

This raises the question of the L1 community which, in an immigrant setting, can take various forms: a) either the immigrant has no contact with other immigrants in the host country and any confirming evidence comes from the home country, b) or she is a member of an immigrant community which will be the source of at least part of the confirming evidence and new SCCCs. It has been proposed recently (Köpke 2004b) that these two sorts of cultural contexts may have different consequences for attrition:

a. In the case of completely isolated immigrants, L1 use is reduced to a necessarily limited amount of contact with L1 speakers in the home country and, possibly, books, TV, and Internet. The SCCCs related to L1 will become weaker and weaker, but they remain those of the L1 community in the home country. The linguistic norms on which the L1 competence is based will not change, but L1 will be more and more difficult to access since its activation level will decrease as L1 becomes dormant (Green 1986); hence this case of attrition will mainly be a question of control over intact knowledge, i.e. performance attrition.

b. If the immigrant is part of an immigrant community in the host country, she will be exposed to different kinds of input: possibly to input from the L1 community in the home country as in case a), but also to input from the immigrant community, including attrited speech and different learner varieties from 2 nd and 3rd generation speakers. The amount of contact will probably be greater than in case a) due to regular L1 input in the migrant setting via clubs, churches, contact with other migrants, community newspapers, etc., but the input will comprise much more structural variation. Moreover, the contact with other migrants who live in close contact with another language is likely to lead to new SCCCs (better adapted to the L2 culture) and to the development of a contact variety, as has been observed by Grosjean \& Py (1991) for Spanish immigrants in Neuchâtel, or by Montrul (2004) or SilvaCorvalan (1991) for Spanish speaking immigrants in the USA. In such a case, attrition will involve a restructuring of L1 competence due to the development of new L1 norms in the contact situation. This could furthermore be enhanced by the possibility to communicate in a bilingual mode (Grosjean 1992) characterised by massive code switching which may also have consequences on inhibitory control in a largely bilingual context (see 1.3. above).

The issue of language use and contact certainly needs to be investigated further in the context of attrition (see Schmid, this volume). Nevertheless, the predictions arising from these thoughts on the 
type of language use as a function of the cultural context of the immigrant are that attrition may be either more performance-oriented or more competence-oriented (Köpke 2004b: 1341), depending on whether the L1 contact is mainly with members of the L1 community in the country of origin, or with other immigrants in the host country. But this is obviously also a question of attitudes to the L1 norms and to the community.

\subsection{Attitudinal factors}

Attitudinal factors include a complex variety of values attributed by the community or the social environment to the languages (L1 and L2) as well as issues like bilingualism, immigration, integration, etc. (see Ben Rafael \& Schmid this volume). These values may or may not be identical with the internal values the subject subscribes to (see 1.4 and Schumann 1997), but they will in all cases have some influence on these internal values and on the motivation to acquire L2 and/or to maintain L1.

Motivation usually arises from external factors such as the socio-economic or ideological context. One example illustrating how integrative or instrumental motivation (Gardner \& Lambert 1972) are dependent on this kind of context is given by Ben Rafael \& Schmid (this volume) for different groups of immigrants in Israel: whereas the Francophone immigrants arrived in Israel during a period where the exclusive use of Hebrew was an ideological imperative, language maintenance is much higher among more recent Russian immigrants who have a more economic and hence instrumental motivation, allowing for the maintenance of Russian as a family language ${ }^{4}$.

Other aspects of motivation may be directly linked to age: for example, adults differ from children in that L1 is an important part of their identity that cannot easily be abandoned. On the other hand, a very young child does not have the same motivation with respect to language as a child of school age who is much more oriented to the peer group than to the family. School children should therefore be most prone to attrition since they are the age group most motivated to integrate into the L2 environment. However, age and previously-acquired literacy skills in L1 might counteract such a tendency.

Still another type of attitude and motivation may depend on the migrant's view of the immigrant situation, and will be directly linked to the cultural context as discussed in 3.2. It includes the immigrants' attitudes with respect to language competence and bilingualism, their origins, and their integration into the L2 community: Is a need felt to be a 'perfect' speaker of each language? Does the speaker accept codeswitching as a bilingual communication mode or is she opposed to language mixing? Is L1 attrition seen as a logical consequence of integration into the L2 community or is it

\footnotetext{
${ }^{4}$ Of course it cannot be excluded that other factors, as for example group size, interact with motivation in this case.
} 
felt as the loss of some aspect of an immigrant's personality? These and other questions (see Pavlenko 2005 for more examples) contribute to a very complex picture of the immigrants' relation with their languages, which will influence language embodiment. Matters are further complicated by the fact that the predictions arising from this are as numerous as the personal configurations are variable.

It appears nonetheless that external factors are of crucial importance in attrition. Even if attrition as a process is based on brain mechanisms and cognitive processes, external factors are most likely to play a major role in determining whether there will be attrition, to what extent, and what type of attrition will occur.

\section{General discussion}

What emerges clearly from the discussion of these various predictions is that attrition is dependent on a large variety of factors. Further complications arise from the fact that many of the factors involved weaken or even cancel each other out. Nevertheless, two strong tendencies emerge:

1. Internal and external factors may have an impact on either amount of attrition, type of attrition, or both: it is proposed here that it is crucial to distinguish factors with quantitative effects, which will play a role in the extent of attrition, and others which will be involved in the qualitative distinction of different attrition phenomena.

2. Moreover, among the most important factors influencing attrition, it is possible to isolate some which seem to be more central than others because they appear to be composite factors related to many others. For example, age and cultural context are complex variables related to many of the other factors. It is further suggested that none of these cluster factors alone may account for L1 attrition.

\subsection{Quantitative vs. qualitative influence on attrition}

The first observation is that some factors influence amount of attrition whereas others may have an impact on type of attrition. Obviously, many cases do not allow for clear-cut distinctions-age, for example, may be found in both categories since it is one of the most important cluster factors. The distinction between quantitative and qualitative impact is nevertheless useful because of its theoretical implications. 
Among the factors that will have an impact on amount of attrition (i.e. How strongly is the subject's L1 affected?) are:

- age in relation to plasticity and literacy (e.g. children generally have more difficulties and undergo attrition more quickly);

- frequency of language use in relation to its consequences for activation thresholds (e.g. people who make less use of L1 are supposed to be more vulnerable to attrition);

- emotional impact in relation to motivation may strengthen attrition effects

Still, the same factors and some others may also account for qualitative distinctions between different attrition types:

- age in relation to type of memory involved (declarative vs. procedural) will have an impact on the parts of the linguistic system that may be involved: in older subjects, attrition will mostly affect those structures which are subserved by declarative memory, in younger subjects attrition will also extend to implicit linguistic competence (i.e. grammar and phonology) subserved by procedural memory;

- type of language use and its consequences on inhibition patterns will favour attrition patterns in this respect: no or little L1 use in purely monolingual settings will lead to processing difficulties, i.e. performance attrition; L1 use in bilingual settings may bring about less performance attrition but there may be competence attrition involving a restructuring of linguistic competence, otherwise observed only in children;

- the cultural context may furthermore strengthen this distinction between competence and performance attrition in relation to the characteristics of the immigrant community (if there is one) and the prevailing attitudes with respect to bilingualism, code switching, attrition, the respective language communities etc.

Attrition research so far has focussed on the quantitative effects of extralinguistic factors. It appears crucial to realize that different attrition types may arise, depending on whether the immigrant is a child or an adult at the onset of bilingualism and/or attrition, and whether she is part of an immigrant community or not. Arguably the term 'attrition' in the sense of an individual phenomenon related to psycholinguistic processes such as language acquisition, learning or pathology is justified only with respect to attrition arising in isolated immigrants (children or adults) - everything happening within the context of a community is likely to be the development of a contact variety which is a sociolinguistic phenomenon related to language change and should be distinguished from individual attrition. 
The second observation is that some factors seem to constitute clusters composed of several factors. Age is one of the best examples of a cluster factor encompassing others. It has been shown that age has consequences on (a) brain plasticity, (b) on the type of memory structures involved in language learning and language processing (declarative or procedural), (c) on the cognitive grounding of language through its close correlation with literacy and education (involving higher metalinguistic knowledge which is of course also linked to b), (d) on motivation, since the relations and expectations between the subject and her environment are also partly related to age, and (e) language use, which also varies as a function of age. The same is likely to apply to a number of other factors related to attrition. This is perhaps the reason why maturational constraints have been shown to play such an important role in attrition (e.g. reviews in Francis 2005; Kaufman 2000).

The linguistic and cultural environment can also be considered a cluster factor. Attrition is a response to a change in the linguistic environment of the emigrant. It is the linguistic environment that will provide the opportunities to use a language - whatever the person chooses to do with that opportunity. So the linguistic environment provides a certain amount of contact with the L1, but it also delivers a certain type of input in the language. We have seen that both will have consequences for activation and inhibition mechanisms. Furthermore, the linguistic environment will also transmit language attitudes and cultural values that will influence the attitudes, motivation and general emotional value systems of the immigrant.

If there is less evidence for these latter factors in the attrition literature than for maturational aspects, the main reason is that the linguistic and cultural environment, and, a fortiori, emotional aspects are more difficult to compare across studies or in literature reviews than the distinction between children and adults. At this level, measures developed for other fields - e.g. Ethnolinguistic Vitality Theory measures developed for ethnic group comparisons (Giles, Bourhis \& Taylor 1977), Social Network Theory (Milroy 1987), or motivational and attitudinal measures largely developed for language learning in classroom settings (Gardner \& Lambert 1972) — are usually not suited for the attrition situation and the development of specifically adapted instruments is needed (for a more detailed discussion see Köpke \& Schmid 2004; Schmid this volume). Despite this gap, it has been shown that emotional factors may outweigh even such well-established variables as age in attrition (e.g. Schmid 2002).

It can therefore be concluded that, even if some factors form clusters that are closely linked to a great number of others, there is no one individual factor, or cluster, that might be considered 
dominant $^{5}$. Rather, it appears that attrition should be considered within a multi-componential view, outlined in figure 1. Each factor, cluster, or type of factor (e.g. biological, cognitive, or external as proposed here by way of example), contributes with its specific weight arising from the individual situation. The sum of the weight of each will determine whether or not there will be attrition and if so to what degree. Note that, following such a conception, levels of proficiency that are similar on the surface level may rely on completely different underlying neuropsychosociological configurations. In some cases (as in Language Proficiency B), biological factors (such as plasticity) may be unfavourable to the maintenance of L1 (in the sense of great plasticity in a young child predicting high attrition), but external factors will be highly favourable to L1 maintenance (e.g. very positive attitudes and stimulating L1 use); in other cases (as in Proficiency Level A) it may turn out the other way round with a similar result. Only when several components are unfavourable will there be a perceptible change in overall language proficiency. This might explain why attrition in adults is generally so hard to measure: in many cases, the overall proficiency may remain within a native-like range (see Hyltenstam \& Abrahamsson 2003 for a discussion of native-like proficiency; and the suggestions made by de Bot this volume).

- insert figure 1 about here -

\section{Conclusion}

The preceding discussion on different kinds of internal and external factors related to L1 attrition allows some tentative conclusions and indications for the future direction of research:

- Attrition in individual settings is a phenomenon different from the development of a contact variety likely to arise in any setting where an immigrant is exposed to a large variety of L1 input influenced by the contact language (L2). The restructuring of linguistic competence observable in such cases entails a modification of the linguistic norms (cf. Py 1986), but bears little resemblance to a psycholinguistic process. It is furthermore suggested that L1 attrition may be of two types: either affecting online processing and performance (as observed in most studies with adults), or entailing a restructuring of the content of the subject's grammar (as demonstrated in some studies, mostly involving children).

- Some factors involved in L1 attrition are stronger than others due to their multiple links with others, forming "cluster factors", but whatever their strength, there is no one individual

\footnotetext{
${ }^{5}$ Note that I have excluded "Aptitude" from this discussion, not so much because it is not really important, but because there are no studies at present, and it seems not to be related to other factors.
} 
factor or cluster able to account for the attrition phenomenon on its own. Attrition needs to be considered within a multi-component view, relying unavoidably on the complementary contribution of several disciplines of the humanities.

In other words, what follows clearly from these considerations is that attrition cannot be conceived as an 'abnormal condition', characterised by very specific symptoms and ascribable to one principal organic cause. Rather, attrition could be described as a type of variety within the language proficiency of multilinguals ${ }^{6}$, arising from a multiplicity of causes and, more often than not, remaining within the range of perceived native-like proficiency.

\section{Acknowledgement}

I am grateful to Monika S. Schmid, Jean-Luc Nespoulous, Angelika Rieussec and two anonymous reviewers for their helpful comments on earlier versions of this paper. I would further like to thank Bert Brouwestijn for his help with the figure.

\section{References}

Abrahamsson, N. \& Hyltenstam, K. (2005). "Grammaticality judgment and language learning aptitude”. International Symposium on Age and Near-nativeness in L2 Acquisition and L1 Attrition. Stockholm: 2nd December 2005.

Altenberg, E. P. \& Vago, R. M. (2004). “The role of grammaticality judgements in investigating first language attrition: A crosslinguistic perspective”. In M. S. Schmid, B. Köpke, M. Keijzer \& L. Weilemar (Eds.), First Language Attrition: Interdisciplinary perspectives on methodological issues (pp. 105-129) Amsterdam: John Benjamins.

Ammerlaan, T. (1996). "You Get a Bit Wobbly... Exploring bilingual lexical retrieval processes in the context of first language attrition”. Unpublished Doctoral Dissertation, Nijmegen: Katholieke Universiteit Nijmegen.

Anderson, M. C. (2003). "Rethinking interference theory: Executive control and the mechanisms of forgetting”. Journal of Memory and Language, 49, 415-445.

As, A. (1963). "The recovery of a forgotten language knowledge through hypnotic age regression: A case report”. American Journal of Clinical Hypnosis, 5, 24-29.

\footnotetext{
6 This conception is largely influenced by Hyltenstam \& Abrahamsson's hypothesis of 'non-perceivable non-native proficiency levels' with respect to ultimate attainment in L2 learners (Hyltenstam \& Abrahamsson 2003: 572).
} 
Baddeley, A. (1986). Working Memory. Oxford: Oxford University Press.

Baddeley, A. (2000). “The episodic buffer: A new component of working memory?". Trends in Cognitive Science, 4 (11), 417-423.

Baddeley, A. (2003). "Working memory: Looking back and looking forward". Nature Reviews Neuroscience, 4 (10), 829-839.

Bahrick, H. P. (1984). "Fifty years of second language attrition: Implications for programmatic research”. The Modern Language Journal, 68 (2), 105-118.

Ben Rafael, M. (2004). "Language contact and attrition: The spoken French of Israeli Francophones". In M. S. Schmid, B. Köpke, M. Keijzer \& L. Weilemar (Eds.), First Language Attrition: Interdisciplinary perspectives on methodological issues (pp. 165-188) Amsterdam: John Benjamins.

Ben Rafael, M. (forthcoming). "Language attrition and ideology in Israel. Francophone kibbutzniks compared to Russian immigrants."

Berg, T. \& Schade, U. (1992). "The role of inhibition in a spreading-activation model of language production. I. The psycholinguistic perspective”. Journal of Psycholinguistic Research, 21 (6), 405-434.

Bialystok, E. \& Sharwood Smith, M. (1985). "Interlanguage is not a state of mind: An evaluation of the construct for second-language acquisition”. Applied Linguistics, 16, 101-117.

Birdsong, D. (1992). “Ultimate attainment in second language acquisition. Language, 68, 706-755.

Boujon, C. (2002). L'inhibition au carrefour des neurosciences et des sciences de la cognition. Marseille: Solal.

Carroll, J. B. (1973). "Implications of aptitude test research and psycholinguistic theory for foreign language teaching”. International Journal of Psycholinguistics, 2, 5-14.

Chomsky, N. (1965). Aspects of the Theory of Syntax. Cambridge, MA: MIT Press.

Collette, F., van der Linden, M. \& Poncelet, M. (2000). "Working memory, long-term memory and language processing: Issues and future directions". Brain and Language, 71, 46-51.

Cook, V. (1992). "Evidence for multicompetence”. Language Learning, 42, 557-591.

Crosson, B., Novack, T. A. \& Trenerry, M. R. (1988). "Subcortical language mechanisms: Window on a new frontier". In H. A. Whitaker (Ed.), Phonological Processes and Brain Mechanisms (pp. 24-58). New York, NY: Springer Verlag.

Damasio, A. R. (2003). Spinoza avait raison. Joie et tristesse, le cerveau des émotions. Paris: Odile Jacob.

Daneman, M. \& Carpenter, P. A. (1980). "Individual differences in working memory and reading”. Journal of Verbal Learning and Verbal Behavior, 19, 450-466. 
De Bode, S. (1996). First Language Attrition: Productive morphology disintegration and neurobiological support. A case study. Unpublished MA Thesis, Pomona, CA: California State University.

de Bot, K. (2001). "Language use as an interface between sociolinguistic and psycholinguistic processes in language attrition and language shift". In J. Klatter-Folmer \& P. van Avermaet (Eds.), Theories on Maintenance and Loss of Minority Languages: Towards a more integrated explanatory framework (pp. 65-82). Münster: Waxmann.

de Bot, K. \& Stoessel, S. (2000). "In search of yesterday's words: Reactivating a forgotten language". Applied Linguistics, 21 (3), 364-384.

de Bot, K. \& Weltens, B. (1991). "Regression, recapitulation, and language loss". In H.W. Seliger, \& R.M. Vago (Eds.), First Language Attrition (pp. 31-52). Cambridge: Cambridge University Press.

Dell, G. S. (1986). "A spreading-activation theory of retrieval in sentence production". Psychological Review, 93, 283-321.

Dressler, U. (1991). "The sociolinguistic and patholinguistic attrition of Breton phonology, morphology, and morphophonology". In H.W. Seliger, \& R.M. Vago (Eds.), First Language Attrition (pp. 99-112). Cambridge: Cambridge University Press.

Dussias, P. (2004). "Parsing a first language like a second: The erosion of L1 parsing strategies in Spanish-English bilinguals". International Journal of Bilingualism, 8 (3), 355-371.

Ecke, P. (2004). "Language attrition and theories of forgetting: A cross-disciplinary review". International Journal of Bilingualism, 8 (3), 321-354.

Ellis, N. (1994). "Implicit and explicit language learning: An overview”. In N. Ellis (Ed.), Implicit and Explicit Learning of Languages (pp. 1-31). New York, NY: Academic Press.

Fabbro, F. (1999). The Neurolinguistics of Bilingualism. An introduction. Hove: Psychology Press.

Flege, J. E., Yeni-Komshian, G. \& Liu, S. (1999). "Age constraints on second-language acquisition”. Journal of Memory and Language, 41, 78-104.

Fodor, J. \& Garrett, M. (1966). “Some reflections on competence and performance”. In J. Lyons \& R. J. Wales (Eds.), The Edinburgh Conference on Psycholinguistics (pp. 135-182). Edinburgh: Edinburgh University Press.

Francis, N. (2005). "Research findings on early first language attrition: Implications for the discussion on critical periods in language acquisition". Language Learning, 55 (3): 491-531.

Fromm, E. (1970). "Age regression with unexpected reappearance of a repressed childhood language". International Journal of Clinical and Experimental Hypnosis, 18, 79-88.

Gardner, R. C. \& Lambert, W. E. (1972). Attitudes and Motivations in Second Language Learning. Rowley, MA: Newbury House. 
Giles, H., Bourhis, R. Y. \& Taylor, D. M. (1977). “Towards a theory of language in ethnic group relations”. In H. Gildes (Ed.), Language, Ethnicity and Intergroup Relations (pp. 307-348). New York, NY: Academic Press.

Grainger, J. \& Dijkstra, T. (1992). "On the representation and use of language information in bilinguals". In R. J. Harris (Ed.) Cognitive Processing in Bilinguals (pp. 207-220). Amsterdam: North Holland.

Green, D. W. (1986). "Control, activation, and resource: A framework and a model for the control of speech in bilinguals". Brain and Language, 27, 210-223.

Green, D. W. (1993). “Towards a model of L2 comprehension and production”. In R. Schreuder \& B. Weltens (Eds.), The Bilingual Lexicon (pp. 249-278). Amsterdam: John Benjamins.

Green, D. W. (1998a). "Mental control of the bilingual lexico-semantic system". Bilingualism: Language and Cognition, 1, 77-82.

Green, D. W. (1998b). "Schemas, tags and inhibition”. Bilingualism: Language and Cognition, 1, 100-104.

Grosjean, F. (1988). "Exploring the recognition of guest words in bilingual speech". Language and Cognitive Processes, 3, 233-274.

Grosjean, F. (1992). “Another view of bilingualism”. In R. J. Harris (Ed.), Cognitive Processing in Bilinguals (pp. 51-62). Amsterdam: North Holland.

Grosjean, F. \& Py, B. (1991). “La restructuration d'une première langue: l'intégration de variantes de contact dans la compétence de migrants bilingues". La Linguistique, 27, 35-60.

Gross, S. (2004). "A modest proposal: Explaining language attrition in the context of contact linguistics”. In M. S. Schmid, B. Köpke, M. Keijzer \& L. Weilemar (Eds.), First Language Attrition: Interdisciplinary perspectives on methodological issues (pp. 281-298). Amsterdam: John Benjamins.

Gürel, A. (2002). Linguistic Characteristics of Second Language Acquisition and First Language Attrition: Turkish overt versus null pronouns. Unpublished Doctoral Dissertation, Montreal: McGill University.

Gürel, A. (2004). "Selectivity in L2-induced L1 attrition: A psycholinguistic account". Journal of Neurolinguistics, 17 (1), 53-78.

Håkansson, G. (1995). "Syntax and morphology in language attrition: A study of five bilingual expatriate Swedes". International Journal of Applied Linguistics, 5 (2), 153-171.

Hulsen, M. (2000). Language Loss and Language Processing: Three generations of Dutch migrants in New Zealand. Unpublished Doctoral Dissertation, Nijmegen: Katholieke Universiteit Nijmegen. 
Hyltenstam, K. \& Abrahamsson, N. (2003). "Maturational constraints in SLA". In C. Doughty \& M.H. Long (Eds.), Handbook of Second Language Acquisition (pp. 539-588). Oxford: Blackwell.

Ijalba, E., Obler, L. K. \& Chengappa, S. (2004). "Bilingual aphasia”. In T. K. Bathia \& W. C. Ritchie (Eds.), The Handbook of Bilingualism (pp. 71-89). Malden, MA: Blackwell.

Isurin, L. (2000). "Deserted islands or a child's first language forgetting”. Bilingualism: Language and Cognition, 3, 151-166.

Jakobson, R. (1941). Kindersprache, Aphasie und allgemeine Lautgesetze. Uppsala: Almqvist and Wiksell.

Johnson, J. S. \& Newport, E. L. (1989). “Critical period effects in second language learning: the influence of maturational state on the acquisition of English as a second language". Cognitive Psychology, 21, 60-99.

Just, M. A. \& Carpenter, P. N. (1992). “A capacity theory of comprehension: Individual differences in working memory". Psychological Review, 99, 122-149.

Kaufman, D. (2000). “Attrition of Hebrew in the United States: Sociolinguistic perspectives". In E. Olshtain (Ed.), Immigration, Identity, and Language (pp. 409-420). Jerusalem: Magnes Publications Hebrew University.

Kaufman, D. \& Aronoff, M. (1991). "Morphological disintegration and reconstruction in first language attrition”. In H.W. Seliger \& R. M. Vago (Eds.), First Language Attrition (pp. 175-188). Cambridge: Cambridge University Press.

Keijzer, M. C. J. (2004). "First language attrition: A cross-linguistic investigation of Jakobson's regression hypothesis". International Journal of Bilingualism, 8 (3), 389-393.

Köpke, B. (1999). L'attrition de la première langue chez le bilingue tardif: implications pour l'étude psycholinguistique du bilinguisme. Unpublished Doctoral Dissertation, Toulouse: Université du Mirail.

Köpke, B. (2001). "Quels changements linguistiques dans l'attrition de la L1 chez le bilingue tardif?" TRANEL, 34/35, 355-368.

Köpke, B. (2002). “Activation thresholds and non-pathological first language attrition". In F. Fabbro (Ed.), Advances in the Neurolinguistics of Bilingualism (pp. 119-142). Udine: Forum University Press.

Köpke, B. (2004a). “Neurolinguistic aspects of attrition”. Journal of Neurolinguistics, 17 (1), 3-30.

Köpke, B. (2004b). "Attrition is not a unitary phenomenon: On different possible outcomes of language contact situations". In A. M. L. Suarez, F. Ramallo \& X-P. Rodiguez-Yanez (Eds.), Bilingual Socialization and Bilingual Language Acquisition: Proceedings from the 
Second International Symposium on Bilingualism (pp. 1331-1347). Vigo: Servizo de Publicacions da Universitdade de Vigo. (http://webs.uvigo.es/ssl/actas2002/).

Köpke, B. \& Schmid, M.S. (2004) "First language attrition: The next phase.” In M. S. Schmid, B. Köpke, M. Keijzer \& L. Weilemar (Eds.), First Language Attrition: Interdisciplinary perspectives on methodological issues (pp. 1-43). Amsterdam: John Benjamins.

Krashen, S. (1981). Second Language Acquisition and Second Language Learning. Oxford: Pergamon Press.

Lamendella, J. (1977). "General principles of neurofunctional organization and their manifestation in primary and secondary language acquisition”. Language Learning, 27, 155-196.

Lenneberg, E. H. (1967). Biological Foundations of Language. New York, NY: Wiley.

Levine, G. (1996). "Elderly second-generation speakers of Yiddish: Toward a model of L1 loss, incomplete L1 acquisition, competence, and control". Southwestern Journal of Linguistics, 15 (1), 109-120.

Luria, A. R. (1966). The Higher Cortical Functions in Man. New York, NY: Basic Books.

Luria, A. R. (1974). "Basic problems in neurolinguistics”. In T. A. Sebeok (Ed.), Current Trends in Linguistics (pp. 2561-2593). The Hague: Mouton.

MacLeod, C. M. (1976). "Bilingual episodic memory: Acquisition and forgetting”. Journal of Verbal Learning and Verbal Behavior, 15, 347-364.

Major, R. C. (1992). "Losing English as a first language”. The Modern Language Journal, 76 (2), 190-208.

McCarthy, R. A. \& Warrington, E. K. (1994). Neuropsychologie cognitive. Une introduction clinique. Paris: Presses Universitaires de France.

McClelland, J. L. \& Rumelhart, D. E. (1981). “An interactive activation model of context effects in letter perception: Part 1. An account of the basic findings". Psychological Review, 88, 375407.

McClelland, J. L. \& Elman, J. L. (1986). “The TRACE model of speech perception”. Cognitive Psychology, 18, 1-86.

Meara, P., Milton, J. \& Lorenzo-Dus, N. Swansea Language Aptitude Test (LAT) v2.0 (Lognostics, Swansea, 2003).

Meuter, R. \& Humphreys, G. (1997). “The frontal lobe and bilingual switching: Asymmetrical costs of language selection”. International Workshop on the Psycholinguistics of Bilingualism, Université de Provence: 20-21 May 1997.

Milroy, L. (1987). Language and Social Networks. Oxford: Blackwell. 
Montrul, S. (2004). "Convergent outcomes in L2 acquisition and L1 loss". In M. S. Schmid, B. Köpke, M. Kejzer \& L. Weilemar (Eds.), First Language Attrition: Interdisciplinary perspectives on methodological issues (pp. 259-280). Amsterdam: John Benjamins.

Nespoulous, J-L. (1994). "Le langage: Introduction. Linguistique, neurolinguistique et neuropsycholinguistique". In M. Jeannerod \& X. Seron (Eds.), Neuropsychologie Humaine (pp. 317-319). Bruxelles: Mardaga.

Nicoladis, E. \& Grabois, H. (2002). "Learning English and losing Chinese: A study of a child adopted from China”. International Journal of Bilingualism, 6 (4), 441-454.

Norman, D. \& ShalliceT. (1986). “Attention to action: Willed and automatic control of behavior”. In R. J. Davidson, G. E. Schartz \& D. Shapiro (Eds.), Consciousness and Self-regulation vol. 4 (pp. 1-18). New York, NY: Plenum.

Olshtain, E. (1986). "The attrition of English as a second language with speakers of Hebrew”. In B. Weltens, K. de Bot \& T. van Els (Eds.), Language Attrition in Progress (pp. 185-204). Dordrecht: Foris.

Olshtain, E. \& Barzilay, M. (1991). "Lexical retrieval difficulties in adult language attrition”. In H. W. Seliger \& R. M. Vago (Eds.), First Language Attrition (pp. 139-150). Cambridge: Cambridge University Press.

Opitz, C. (2005). "Trade-offs between language proficiencies as a cause of L2 attrition". Second International Conference on First Language Attrition. Amsterdam: 17-20 August 2005.

Pallier, C., Dehaene, S., Poline, J.-B., LeBihan, D., Argenti, A.-M., Dupoux, E. \& Mehler, J. (2003). "Brain imaging of language plasticity in adopted adults: Can a second language replace the first?" Cerebral Cortex, 13, 155-161.

Paradis, M. (1985) “On the representation of two languages in the brain”. Language Sciences, 7 (1), 1-39.

Paradis, M. (1993) "Linguistic, psycholinguistic, and neurolinguistic aspects of "interference" in bilingual speakers: The Activation Threshold Hypothesis". International Journal of Psycholinguistics, 9 (2), 133-145.

Paradis, M. (1994). "Neurolinguistic aspects of implicit and explicit memory: Implications for bilingualism and SLA”. In N. Ellis (Ed.), Implicit and Explicit Learning of Languages (pp. 393-419). New York, NY: Academic Press.

Paradis, M. (1997). “The cognitive neuropsychology of bilingualism”. In A. M. B de Groot \& J. Kroll (Eds.), Tutorials in Bilingualism: Psycholinguistic perspectives (pp. 331-354). Hillsdale, NJ: Lawrence Earlbaum Associates.

Paradis, M. (2004). A Neurolinguistic Theory of Bilingualism. Amsterdam: John Benjamins. 
Pavlenko, A. (2003). “'I feel clumsy speaking Russian': L2 influence on L1 narratives of Russian L2 users of English". In V. Cook (Ed.), L2 Influence on L1 (pp. 32-61). Clevedon: Multilingual Matters.

Pavlenko, A. (2005). Emotions and Multilingualism. Cambridge: Cambridge University Press.

Penfield, W. \& Roberts, L. (1959). Speech and Brain Mechanisms. New York, NY: Atheneum.

Py, B. (1986). "Native language attrition amongst migrant workers: Towards an extension of the concept of interlanguage". In E. Kellermann \& M. Sharwood Smith (Eds.), Crosslinguistic Influence in Second Language Acquisition (pp. 163-172). New York, NY: Pergamon Press.

Rieussec, A. \& Köpke, B. (2005). “Conceptual bridges between attrition and L2 learning”. Second International Conference on First Language Attrition. Amsterdam: 17-20 August 2005.

Rieussec, A. \& Köpke, B. (2007). "Cognitive flexibility in lexical retrieval: Comparing L2 acquisition and L1 attrition in German”. ISB 4. Hamburg: 30 May - 2 June 2007.

Schmid, M. S. (2002). First Language Attrition, Use, and Maintenance: The case of German Jews in Anglophone countries. Amsterdam: John Benjamins.

Schmid, M. S. (2004). "Le rôle du système linguistique: attrition vs. contact de langues et changement linguistique". Journée 'Quand la sociolinguistique rencontre la neurolinguistique: l'exemple de l'attrition. Toulouse: Université Toulouse-Le Mirail, 28 Mai 2004.

Schmitt, E. (2004). "No more reductions! To the problem of evaluation of language attrition data". In M. S. Schmid, B. Köpke, M. Keijzer \& L. Weilemar (Eds.), First Language Attrition: Interdisciplinary perspectives on methodological issues (pp. 299-316). Amsterdam: John Benjamins.

Schumann, J.H. (1997). The Neurobiology of Affect in Language. Malden, MA: Blackwell.

Seliger, H. W. (1991). "Language attrition, reduced redundancy, and creativity”. In H. W. Seliger \& R. M. Vago (Eds.), First Language Attrition (pp. 227-240). Cambridge: Cambridge University Press.

Sharwood Smith, M. (1983). "On explaining language loss”. In S. Felix \& H. Wode (Eds.), Language Development on the Crossroads (pp. 49-69). Tübingen: Gunter Narr.

Sharwood Smith, M. \& van Buren, P. (1991). "First language attrition and the parameter setting model”. In H. W. Seliger \& R. M. Vago (Eds.), First Language Attrition (pp. 17-30). Cambridge: Cambridge University Press.

Silva-Corvalan, C. (1991). "Spanish language attrition in a contact situation with English”. In H. W. Seliger \& R. M. Vago (Eds.), First Language Attrition (pp. 151-174). Cambridge: Cambridge University Press 
Speedie, L. J., Wertman, E., Ta'ir, J. \& Heilman, K. M. (1993). “Disruption of automatic speech following a right basal ganglia lesion”. Neurology, 43, 1768-1774.

Sperber, D. \& Hirschfeld, L. (to appear). "Culture and modularity”. In P. Carruthers, S. Laurence \& S. Stich (Eds.), The Innate Mind: Culture and cognition. Oxford: Oxford University Press. (accessed on http://www.dan.sperber.com/texts-culture.htm in October 2006)

Swain, M. (2000). "The output hypothesis and beyond: Mediating acquisition through collaborative dialogue". In J. P. Lantolf (Ed.), Sociocultural Theory and Second Language Learning (pp. 97-114). Oxford: Oxford University Press.

Turian, D. \& Altenberg, E. P. (1991). “Compensatory strategies of child first language attrition”. In H. W. Seliger \& R. M. Vago (Eds.), First Language Attrition (pp. 207-226). Cambridge: Cambridge University Press.

Ullman, M. T. (2001). "The neural basis of lexicon and grammar in first and second languages: The declarative/procedural model”. Bilingualism: Language and Cognition, 4 (1), 105-122.

van der Linden, M., \& Collette, F. (2002). “Attention et mémoire de travail”. In J. Couillet, M. Leclercq, Ch. Moroni, \& Ph. Azouvi, (Eds.), La neuropsychologie de l'attention (pp. 4154). Marseille: Solal.

Vago, R. M. (1991). “Paradigmatic regularity in first language attrition”. In H. W. Seliger \& R. M. Vago (Eds.), First Language Attrition (pp. 241-252). Cambridge: Cambridge University Press.

Ventureyra, V. (2005). A la recherche de la langue perdue: étude psycholinguistique de l'attrition de la première langue chez des coréens adoptés en France. Unpublished Doctoral Dissertation, Paris: EHESS.

Ventureyra, V., Pallier, C. \& Yoo, H-Y. (2004). “The loss of first language phonetic perception in adopted Koreans". Journal of Neurolinguistics, 17 (1), 79-91.

Yagmur, K. (1997). First Language Attrition among Turkish Speakers in Sidney. Tilburg: Tilburg University Press.

Zobl, H. (1995). "Converging evidence for the 'acquisition-learning' distinction". Applied Linguistics, 16 (1), 35-56. 


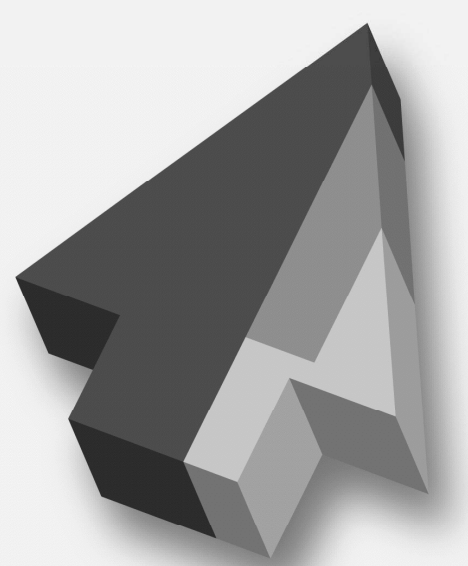

Language proficiency

A

Biological factors

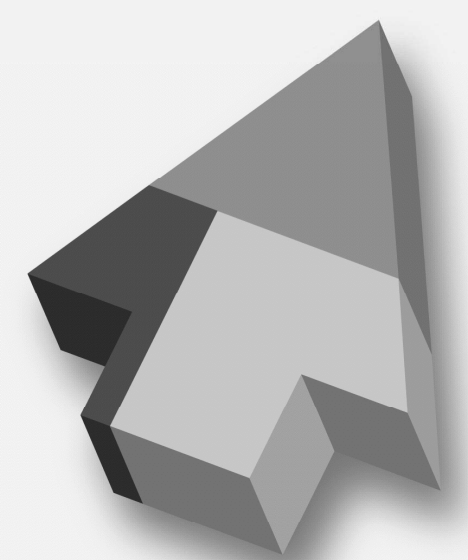

Language proficiency

$B$

Cognitive factors
External factors

Figure 1: A multicomponential view of language proficiency in the context of attrition. 